\title{
Hookah use: Could Families be a risk factor for future addiction?
}

\author{
Nicolette V. Roman, Catherina Schenck, Liezille Jacobs and Shiron Jade September
}

\begin{abstract}
Research indicates that smoking a hookah has health and addiction risks. In substance abuse research the family is often a protective factor in reducing youth substance use. However, this may not be the case for smoking a hookah. The aim of the current study was to examine the use of the hookah in the family. This was a cross-sectional descriptive study of 837 South African adult participants, $51.7 \%$ males and $48.3 \%$ females. The mean age of participants was 35.29 (SD D 15.11) years. The results indicate that families not only expose children younger than 18 years to using the hookah in the family, but children also experience the use of the hookah. Participants also indicated that other substances were used in the hookah. The findings of this study have implications for policy and intervention programs.
\end{abstract}

\section{Introduction}

Smoking tobacco is a global health epidemic and poses a particular risk for children and youths, and therefore countries are encouraged to adopt a plan for prevention and intervention as indicated by the World Health Organization (WHO, 2013). Previous research suggests that early age of onset of tobacco use is problematic for later substance use (Nelson, Van Ryzin, \& Dishion, 2015) and that families pose a risk factor for adolescent use (Miller \& Volk, 2002; WHO, 2013). Due to countries implementing tobacco control policies (WHO, 2013), tobacco smokers find alternative ways of smoking tobacco. One such way is smoking tobacco through the hookah, which is also known as the waterpipe.

A recent study review by the World Health Organization (2015) provides an overview of the health hazards of smoking the hookah as well as the research focus areas conducted on the hookah. In addition, the WHO review also highlights the need to study the hookah in different contexts. From a global perspective, we know that the majority of studies have been conducted with university students and youths (WHO, 2015). There have also been studies that compared male and female use, explored cultural contexts, as well as identified the health risks (El-Setouhy et al., 2008; Mohammad, Kayak, \& Mohammad, 2008; Noonan \& Kulbok, 2009). These health risks include lung diseases, cancer, tuberculosis, low birth weight, heart disease, and periodontal disease (Akl et al., 2011; Munckhof, Konstantinos, Wamsley, Mortlock, \& Gilpin, 2003). A global trend has been that the hookah has become a social instrument rather than the cultural instrument it was originally designed for. In addition, there is the common belief that the water filters out the harmful chemicals of the 
tobacco or coal (Ghafouri et al., 2011; Reddy et al., 2010). Thus the belief is that smoking the hookah is not as harmful or addictive as smoking cigarettes (Jackson \& Aveyard, 2008) even though the research indicates that smoking the hookah exposes a user to approximately 36 times the amount of nicotine and an increased concentration of heavy metals than smoking a cigarette (Shihadeh \& Saleh, 2005).

As a health hazard and a public health concern, a growing concern is the age of onset of smoking the hookah and the pathways to addiction of smoking cigarettes (Rice, Templin, \& Kulwicki, 2003; Maziak, 2014; Primack, Aronson, \& Agarwal, 2006) and other substances (Sabahy, Divsalar, \& Nakhee, 2011). The reason for these concerns is that people who did not smoke cigarettes but smoked the hookah are eight times more likely to experiment with smoking cigarettes (Cobb, Ward, Maziak, Shihadeh, \& Eissenberg, 2010). Furthermore, a concern is that if young people start smoking tobacco at an early age, they may be more likely to become addicted to nicotine than those who start later (Primack et al., 2006; Rice et al., 2003). There is the possibility that because this is a social instrument and is permissible in society (WHO, 2005), it may also be acceptable in the home or family environment, which may be a risk for early initiation and subsequent addictive behaviors. Sharing a hookah after meals in some families is perceived as normal behavior (Knishkowy \& Amitai, 2005) and therefore poses a greater risk for hookah use and addiction (Jamil et al., 2011). Thus the family context could be perceived as a risk, rather than a protective, environment.

The family is the focus of the current study as it is within the family that the first processes of socialization occur. The expectation is that the adults in families create protective environments for children. These protective environments may include family attitudes and practices so that children do not engage in risk-taking behavior (Ryan, Roman, \& Okwany, 2015; Telzer, Gonzales, \& Fuligni, 2014). However, families may not necessarily create these protective environments. For example, cigarette smoking is considered taboo (for children and youths) in the family and has been identified as a health hazard, but this may not be the case for smoking the hookah (Maziak, 2011; Maziak, Eissenberg, et al., 2004; Maziak, Eissenberg, \& Ward, 2005; Maziak et al., 2011; Maziak, Ward, Soweid, \& Eissenberg, 2004). Tamim and colleagues (2007) compared parents' awareness of their children smoking cigarettes with those whose children smoked the hookah. For those whose children smoked the hookah, $62.8 \%$ of fathers and $76.1 \%$ of mothers knew about it. For cigarette smokers, $20 \%$ of fathers and $29 \%$ of mothers were aware of their children using it. Jamil and colleagues (2011) found that having a family member smoke tobacco using the hookah at home is a risk factor for smoking tobacco using the hookah. This was similarly found for a recent qualitative study in Iran where the family facilitated the initiation of hookah smoking (Baheiraei, Sighaldeh, Ebadi, Kelishadi, \& Majdzadeh, 2015). Thus, although studies have identified the family as a socially acceptable space for engaging in smoking tobacco using the hookah (Jamil et al., 2011; Maziak, 2014; Tamim et al., 2007), the role of the family in using the hookah to smoke tobacco is not very clear.

In South Africa, there are very strict tobacco control laws (Government of South Africa, 2008) regarding cigarette smoking but not for using the hookah to smoke tobacco. 
Currently, the hookah is used as a social instrument to smoke tobacco, as it is socially permissible and not controlled. There are only six studies over a 10-year period which have been conducted in South Africa (Combrink et al., 2010; Daniels \& Roman, 2013; Naidoo, 2013; Senkubuge, Ayo-Yusuf, Louwagie, \& Okuyemi, 2012; Theron, Schultz, Ker, \& Falzone, 2010; Van Der Merwe et al., 2013) with prevalence rates in studies ranging from $18.6 \%$ to $60 \%$ (Daniels \& Roman, 2013). The South African studies mainly focused on knowledge, perceptions, and attitudes of using the hookah to smoke tobacco among university students and school learners. Naidoo (2013) indicates that having a family member smoke tobacco using the hookah is an associated factor for using the hookah to smoke tobacco. In a South African context, substance abuse and high rates of cigarette smoking, especially among the coloured $^{1}$ population, is a problem especially among youths (Pluddemann et al., 2010) and has huge implications for families. The information on using the hookah to smoke tobacco within the family is globally very limited or inferred (Daniels \& Roman, 2013; Jamil et al., 2011; Maziak, 2014; Tamim et al., 2007). The current study therefore sought to extend previous research by determining the use of the hookah to smoke tobacco within the family in South Africa.

\section{Research method and design}

This cross-sectional descriptive study was conducted in two areas in the Western Cape, South Africa. Area 1 was a conveniently sampled urban area in close proximity to the university and Area 2 was a rural area, which had been identified by a registered community-based organization as an area where age of onset of hookah use was quite early, which may lead to subsequent substance abuse.

\section{Participants}

In both areas a systematic "door-to-door" sampling or recruitment process as identified by Flynn, Tremblay, Rehm, and Wells (2013) was used to select the sample. Zones and entry points were identified by using Google Maps of the areas. An adult living in every fifth house was asked to participate in the study. The final sample consisted of 837 adult South African participants.

\section{Measures}

The questionnaire was adapted from the questionnaire used in a previous Western Cape, South African, study focusing on university students' use of the waterpipe or hookah (with the maasel) (Daniels \& Roman, 2013). The current questionnaire was adapted for exploring use within the family environment. The adapted version for this study included hookah use in the family. These were (a) a demographic section including the gender, age, race, and language of participants and (b) the use of the hookah in the family including who uses the hookah, age of use, where it is used, and which substances are used with the tobacco in the hookah. In terms of age of use, an example of an item included "Are there any children (2 to 6 years) who smoke the hookah pipe in your family?" (response options were "Yes" or "No"). This question was asked to different age groups with the intention of only

\footnotetext{
${ }^{1}$ This term is used to identify a mixed race person in South Africa.
} 
identifying prevalence of use per age group. In terms of using the tobacco with other substances in the hookah, participants were asked, "Is the tobacco in the hookah pipe used together with [alcohol], [dagga]...?" Participants responded "Yes" or "No" to each of the stated substances.

\section{Data collection process}

Permission to conduct the study, ethics clearance, and proposal registration were provided by the Senate Research Committee at the University of the Western Cape. Once permission had been attained, a group of 80 students were trained to administer the questionnaire. Student fieldworkers were divided into groups of four and were assigned to zones in the different areas. They were asked to remain in their groups when collecting data as a means of safety. Student fieldworkers approached a family and invited an adult family member (male or female) to voluntarily participate in the study. Before the participants agreed to participate in the study, they were first provided with an information sheet and consent form, which was explained by the student (fieldworker). Once the participants understood and agreed to voluntarily participate in the study, they were then asked to sign the consent form. Although the questionnaire is self-administered, the student fieldworkers assisted the participants with the completion thereof. This assisted in high rates of completion as well as aiding in literacy challenges. The completion of the questionnaire took approximately 30 minutes.

\section{Dataanalysis}

The Statistical Package for the Social Sciences (SPSS) was used to analyze the data. The statistical analysis included descriptive statistics describing the data including frequencies, means, and standard deviations since this was a descriptive study.

\section{Results}

The results in Table 1 indicate that the majority of participants were male (417;51.7\%), and identified themselves as coloured (being from a mixed race; 701; 88.8\%) and unemployed (502; 62.3\%). The average age of participants was 35.29 years (SD D 15.11), with the youngest participants age 18 years old. The education level of the participants suggests that the majority left school in grade 12. The average age of onset of cigarette smoking (M D 16.23; SD D 4.53) and hookah smoking (M D 17.16; SD D 6.99) were similar. For using the hookah to smoke tobacco the minimum age of onset was five years of age. Table 1 also reflects the current tobacco smoking status of participants. Current cigarette smoking (456; $54.8 \%$ ) was more prevalent than current hookah smoking $(191 ; 23.4 \%)$ among the participants.

Table 2 indicates that dagga is the substance most used with the maasel (or hookah tobacco) in the hookah $(555 ; 70.1 \%)$. This was followed by using alcohol as a replacement for the water in the hookah $(461 ; 58.5 \%)$.

In Table 3 the results suggest that the majority of participants were knowledgeable of smoking tobacco using the hookah $(789 ; 95.5 \%)$. Almost one-third of participants indicated that the hookah was used to smoke tobacco in their families $(18 ; 27.6 \%)$ but of

\section{http://repository.uwc.ac.za}


those whose families used the hookah to smoke tobacco, the majority of the participants indicated that they did not use it in thehome $(128 ; 85.9 \%)$.

In Table 4, the use of the hookah to smoke tobacco in the family was highlighted as being used mainly by a brother $(55 ; 16.7 \%)$ or a sister $(24 ; 7.6 \%)$, who may also be adults in the family. Almost one-quarter of participants indicated that there were children present when the hookah was being used within the family. The prevalence of children smoking tobacco using the hookah in the family increased with age. At least $8 \%$ of the participants indicated that children younger than six years of age were using the hookah to smoke tobacco in the family.

Table 1. Demographic Information of Participants.

\begin{tabular}{|c|c|c|c|c|}
\hline Variables & & & $N$ & $\%$ \\
\hline \multirow[t]{2}{*}{ Gender } & \multicolumn{2}{|c|}{ Males } & 417 & 51.7 \\
\hline & \multicolumn{2}{|c|}{ Females } & 389 & 48.3 \\
\hline \multirow[t]{4}{*}{ Race } & \multicolumn{2}{|c|}{ Coloured } & 701 & 88.8 \\
\hline & \multirow{2}{*}{\multicolumn{2}{|c|}{$\begin{array}{l}\text { White } \\
\text { Black African }\end{array}$}} & 9 & 1.1 \\
\hline & & & 71 & 9.0 \\
\hline & \multicolumn{2}{|c|}{ Indian/Asian } & 8 & 1.0 \\
\hline \multirow[t]{2}{*}{ Employment status } & \multicolumn{2}{|c|}{ Yes } & 305 & 37.7 \\
\hline & \multicolumn{2}{|c|}{ No } & 503 & 62.3 \\
\hline Variable & Minimum & Maximum & $M$ & $S D$ \\
\hline Age & 18 & 86 & 35.29 & 15.11 \\
\hline Age of onset for cigarette smoking & 0 & 47 & 16.23 & 4.53 \\
\hline \multirow[t]{2}{*}{ Age of onset for hookah pipe smoking } & 5 & 59 & 17.16 & 6.99 \\
\hline & \multicolumn{2}{|c|}{ YES } & \multicolumn{2}{|c|}{ NO } \\
\hline Current cigarette smoker & 456 & 54.8 & 376 & 45.2 \\
\hline Current hookah pipe smoker & 191 & 23.4 & 626 & 76.6 \\
\hline
\end{tabular}

Table 2. Additional Substances in the Hookah Pipe.

\begin{tabular}{|c|c|c|c|c|c|c|}
\hline \multirow{2}{*}{$\begin{array}{l}\text { Substances Used With the } \\
\text { Hookah Pipe }\end{array}$} & \multicolumn{2}{|c|}{ Yes } & \multicolumn{2}{|c|}{ No } & \multicolumn{2}{|c|}{ Don't Know } \\
\hline & $N$ & $\%$ & $N$ & $\%$ & $N$ & $\%$ \\
\hline Dagga (Cannabis) & 555 & 70.1 & 96 & 12.1 & 141 & 17.8 \\
\hline Cocaine & 187 & 23.9 & 320 & 41.0 & 274 & 35.1 \\
\hline Heroin & 167 & 21.5 & 326 & 42 & 284 & 36.6 \\
\hline Tik (Meth) & 236 & 30.1 & 306 & 39 & 243 & 31.0 \\
\hline Alcohol & 461 & 58.5 & 156 & 19.8 & 171 & 21.7 \\
\hline
\end{tabular}




\begin{tabular}{|c|c|c|c|c|c|c|}
\hline \multirow[b]{2}{*}{ Hookah Practices Within the Family } & \multicolumn{2}{|c|}{ Yes } & \multicolumn{2}{|c|}{ No } & \multicolumn{2}{|c|}{ Don't Know } \\
\hline & $N$ & $\%$ & $N$ & $\%$ & $N$ & $\%$ \\
\hline Do you know about the hookah pipe? & 789 & 95.5 & 37 & 4.5 & - & - \\
\hline Hookah pipe use in the family & 218 & 27.6 & 553 & 70.1 & 18 & 2.3 \\
\hline If the hookah pipe is used in the family, is it smoked inside your house? & 21 & 14.1 & 128 & 85.9 & - & - \\
\hline
\end{tabular}

\section{Discussion}

The aim of this study was to examine the use of smoking tobacco using the hookah within the family. The results of the current study provide descriptive information regarding the use within the family. This is evidenced in the following way:

In the current study, almost one-quarter of participants indicated that children are present when the hookah is being used, which indicates that children have early exposure to smoke from the hookah as well as smoking tobacco using the hookah. This early exposure to smoking tobacco using the hookah poses a problem as past research suggests that the secondhand smoke from the hookah has harmful effects for everyone present during a hookah session (Almulla, Fanous, Seidenberg, \& Rees, 2014; Maziak, Eissenberg, et al., 2004) and especially children. Furthermore, more recent qualitative research indicates that the adults in the family play a role in the facilitation of the initiation of hookah use due to young people observing family members using the hookah (Baheiraei et al., 2015). The children in the current study may be exposed to secondhand hookah smoke and therefore face the potential health risks of exposure to the chemicals in the hookah tobacco (Fielder, Carey, \& Carey, 2013). Of concern are the risk implications of previous research on early exposure to using the hookah. For example, a study conducted in Jordan found that adolescents who smoked the hookah were more likely to become cigarette smokers rather than those who had never smoked (Jaber et al., 2015). In addition, having just one adult smoking the hookah in the family predicts hookah use among youths (Amrock, Gordon, Zelikoff, \& Weitzman, 2014; Jawad et al., 2013; Naidoo, 2013; Tamim et al., 2007; Weglicki, Templin, Rice, Jamil, \& Hammad, 2008). Thus, if adults in the family are exposing children to the hookah, are children also experiencing the use of it?

In the current study, the average age of onset is approximately 17 years with a minimum age of onset indicated as five years old. In addition, participants also indicated that children between the ages of two and six years old were smoking the hookah. An increase in prevalence use is observed as age increases. Although the age of onset for the current study is similar to previous research (Daniels \& Roman, 2013; Kakodkar \& Bansal, 2013; Maziak, 2014; WHO, 2015), of concern is the possibility that younger children may be using the hookah. Although not tested in the current study, by implication, this study raises possible health and addiction risks as indicated in previous research (Maziak, 2014).

Of grave concern is the current trend to smoke the tobacco with other substances using the hookah. Participants in the current study indicated that alcohol and dagga (cannabis) were the

\section{http://repository.uwc.ac.za}


substances most used in the hookah. These results were similar for previous international and local studies, which indicated the addition of substances to the hookah (Knishkowy \& Amitai, 2005; Sutfin, Song, Reboussin, \& Wolfson, 2014; Van Der Merwe et al., 2013). For example, the water is replaced with alcohol, while drugs replace the tobacco. By implication, the hookah becomes another means of illicit substance use and therefore increases substance abuse and addiction rates among youths. Thus, while smoking the hookah is identified as providing multiple health risks, it is also identified as not only providing the basis for tobacco and nicotine addiction but is potentially also a basis for substance use.

Table 4. Family Members Who Smoke the Hookah Pipe.

\begin{tabular}{|c|c|c|c|c|c|c|}
\hline \multirow[b]{2}{*}{ Who Smokes? } & \multicolumn{2}{|c|}{ Yes } & \multicolumn{2}{|c|}{ No } & \multicolumn{2}{|c|}{ Don't Know } \\
\hline & $N$ & $\%$ & $N$ & $\%$ & $N$ & $\%$ \\
\hline Father & 12 & 3.8 & 302 & 96.2 & - & - \\
\hline Mother & 3 & 1.0 & 307 & 99.0 & - & - \\
\hline Brother & 55 & 16.7 & 275 & 83.3 & - & - \\
\hline Sister & 24 & 7.6 & 293 & 92.4 & - & - \\
\hline Presence of children $<18$ present when the hookah pipe is smoked in the family & 140 & 24.1 & 407 & 70.2 & 33 & 3.9 \\
\hline Children ( $2-6$ years) who smoke the hookah pipe in the family & 43 & 7.5 & 498 & 86.5 & 35 & 6.1 \\
\hline Children (7-10 years) who smoke the hookah pipe in the family & 81 & 14.0 & 467 & 55.8 & 30 & 5.2 \\
\hline Children (11-15 years) who smoke the hookah pipe in the family & 179 & 30.9 & 377 & 65.1 & 23 & 4.0 \\
\hline Children (16-18 years) who smoke the hookah pipe in the family & 224 & 39.0 & 332 & 57.7 & 19 & 3.3 \\
\hline
\end{tabular}

The question is, if there is early exposure to and experience in smoking tobacco using the hookah for children and adolescents within the family, to what extent would this facilitate illicit drug use? This is a question that should be explored in future research studies. It is important to research the concurrent use of other substances in the hookah within the context of parents and families.

There are a few limitations in this study. First, the focus of this study was on one urban and one rural area with the majority of participants being coloured (mixed race). These findings are therefore not representative of other groups of people in South Africa. However, the results of this study should encourage further research into the role of the adult family members in using the hookah to smoke tobacco among youths with a more representative sample of participants. Second, this is a cross-sectional descriptive study and provides only a snapshot of research. The intent of this study is to describe the situation in families. However, future studies should consider other methodological approaches and research designs that could provide inferences regarding this topic. Third, the participants provided subjective reporting in the completion of the questionnaire. Participants may have been inclined to provide socially acceptable answers. Perhaps a qualitative study, with in-depth interviews with both adults and children who smoke tobacco using the hookah, could provide depth to responses. Finally, in this study one adult was asked to provide information regarding the family practices on smoking tobacco using the hookah. The implication of this is that the family member may not necessarily be aware of all the family issues and therefore may not have reported certain practices in line with this study or may have provided socially acceptable answers in order to protect the 
family. However, having additional family members participate in the study could increase the validity and reliability of a similar study.

\section{Conclusion}

The current study findings highlight huge red flags for public health. Using the hookah to smoke tobacco in South Africa is socially acceptable and is not controlled by any laws or policies. The family may facilitate the exposure to and experience with the use of smoking tobacco using the hookah, which has implications for health and future addiction. Interventions should therefore be specifically targeted with families, especially parents, in order to reduce the use of smoking tobacco using the hookah. Given the increasing trend of using the hookah with other substances, policies (both tobacco and substance use) should be revised to restrain the use and sale of it. There should also be a widespread awareness at all levels of society, which would include schools, health facilities, and communities. 


\section{References}

Akl, E. A., Gunukula, S. K., Aleem, S., Obeid, R., Jaoude, P. A., Honeine, R., \& Irani, J. (2011). The prevalence of waterpipe tobacco smoking among the general and specific populations: A systematic review. BMC Public Health, 11(1), 244.

Almulla, A., Fanous, N., Seidenberg, A. B., \& Rees, V. W. (2014). Secondhand smoke emission levels in waterpipe cafes in Doha, Qatar. Tobacco Control, 24(e3):e227-31. doi:10.1136/tobaccocontrol-2014-051717.

Amrock, S. M., Gordon, T., Zelikoff, J. T., \& Weitzman, M. (2014). Hookah use among adolescents in the United States: Results of a national survey. Nicotine \& Tobacco Research, 16(2), 231-237.

Baheiraei, A., Sighaldeh, S. S., Ebadi, A., Kelishadi, R., \& Majdzadeh, R. (2015). The role of family on hookah smoking initiation in women: A qualitative study. Global Journal of Health Science, $7(5), 1$.

Cobb, C., Ward, K. D., Maziak, W., Shihadeh, A. L., \& Eissenberg, T. (2010). Waterpipe tobacco smoking: An emerging health crisis in the United States. American Journal of Health Behavior, 364(3), 275-285.

Combrink, A., Irwin, N., Laudin, G., Naidoo, K., Plagerson, S., \& Mathee, A. (2010). High prevalence of hookah smoking among secondary school students in a disadvantaged community in Johannesburg. South African Medical Journal, 100(5), 297-299.

Daniels, K. E., \& Roman, N. V. (2013). A descriptive study of the perceptions and behaviors of waterpipe use by university students in the Western Cape, South Africa. Tobacco Induced Diseases, 11(1), 4.

Department of Health South Africa. (2010). Tobacco products control amendment bill. Retrieved from http://www.doh. gov.za/docs/bills/tpcab.pdf

El-Setouhy, M., Loffredo, C. A., Radwan, G., Rahman, R. A., Mahfouz, E., Israel, E., \& Ayyad, S. B. (2008). Genotoxic effects of waterpipe smoking on the buccal mucosa cells. Mutation Research/Genetic Toxicology and Environmental Mutagenesis, 655(1), 36-40.

Fielder, R. L., Carey, K. B., \& Carey, M. P. (2013). Hookah, cigarette, and marijuana use: A prospective study of smoking behaviors among first-year college women. Addictive Behaviors, 38(11), 2729-2735.

Flynn, A., Tremblay, P. F., Rehm, J., \& Wells, S. (2013). A modified random walk door-todoor recruitment strategy for collecting social and biological data relating to mental health, substance use/addictions and violence problems in a Canadian community. The International Journal of Alcohol and Drug Research, 2(2), 7-16.

Ghafouri, N., Hirsch, J. D., Heydari, G., Morello, C. M., Kuo, G. M., \& Singh, R. F. (2011). Waterpipe smoking among health sciences university students in Iran: Perceptions, practices and patterns of use. BMC Research Notes, 4(1), 496.

Government of South Africa. (2008). Tobacco Control Act of 1993. Regulations: Tobacco Products Control Amendment Act No. 63. Government Gazette No. 31790. Retrieved from http://www.gov.za/sites/www.gov.za/files/31790_23.pdf

Jaber, R., Madhivanan, P., Khader, Y., Mzayek, F., Ward, K., \& Maziak, W. (2015). Predictors of waterpipe smoking progression among youth in Irbid, Jordan: A longitudinal study (2008-2011). Drug and Alcohol Dependence, 153, 265-270. doi:10.1016/j.drugalcdep.2015.05.008 
Jackson, D., \& Aveyard, P. (2008). Waterpipe smoking in students: Prevalence, risk factors, symptoms of addiction, and smoke intake. Evidence from one British university. BMC Public Health, 8(1), 174 .

Jamil, H., Janisse, J., Elsouhag, D., Fakhouri, M., Arnetz, J. E., \& Arnetz, B. B. (2011). Do household smoking behaviors constitute a risk factor for hookah use? Nicotine \& Tobacco Research, 13, 384-388.

Jawad, M., Wilson, A., Lee, J. T., Jawad, S., Hamilton, F. L., \& Millett, C. (2013). Prevalence and predictors of water pipe and cigarette smoking among secondary school students in London. Nicotine \& Tobacco Research, 15(12), 2069-2075.

Kakodkar, P. V., \& Bansal, S. S. (2013). Hookah smoking: Characteristics, behavior and perceptions of youth smokers in Pune, India. Asian Pacific Journal of Cancer Prevention, 14(7), 4319-4323.

Knishkowy, B., \& Amitai, Y. (2005). Water-pipe (narghile) smoking: An emerging health risk behavior. Pediatrics, 116(1), e113-e119.

Maziak, W. (2011). The global epidemic of waterpipe smoking. Addictive Behaviors, 36(1), 1-5.

Maziak, W. (2014). The waterpipe: A new way of hooking youth on tobacco. The American Journal on Addictions, 23(2), 103-107.

Maziak, W., Eissenberg, T., Rastam, S., Hammal, F., Asfar, T., Bachir, M. E.,... Ward, K. D. (2004). Beliefs and attitudes related to narghile (waterpipe) smoking among university students in Syria. Annals of Epidemiology, 14(9), 646-654.

Maziak, W., Eissenberg, T., \& Ward, K. D. (2005). Patterns of waterpipe use and dependence: Implications for intervention development. Pharmacology Biochemistry and Behavior, 80(1), 173-179.

Maziak, W., Rastam, S., Shihadeh, A. L., Bazzi, A., Ibrahim, I., Zaatari, G. S.,... Eissenberg, T. (2011). Nicotine exposure in daily waterpipe smokers and its relation to puff topography. Addictive Behaviors, 36, 397-399.

Maziak, W., Ward, K. D., Soweid, R. A., \& Eissenberg, T. (2004). Tobacco smoking using a waterpipe: A re-emerging strain in a global epidemic. Tobacco Control, 13(4), 327-333.

Miller, T. Q., \& Volk, R. J. (2002). Family relationships and adolescent cigarette smoking: Results from a national longitudinal survey. Journal of Drug Issues, 32(3), 945-972.

Mohammad, Y., Kayak, M., \& Mohammad, Y. (2008). Chronic respiratory effect of narguileh Smoking in women from the East Mediterranean region. International Journal of Chronic Obstructive Pulmonary Disease, 3, 405-414.

Munckhof, W. J., Konstantinos, A., Wamsley, M., Mortlock, M., \& Gilpin, C. (2003). A cluster of tuberculosis associated with use of a marijuana water pipe. The International Journal of Tuberculosis and Lung Disease, 7(9), 860-865.

Naidoo, K. D. (2013). Factors associated with hookah pipe smoking among undergraduate students at the University of the Witwatersrand, Johannesburg (Master's thesis). University of Witwatersrand, Johannesburg, South Africa.

Nelson, S. E., Van Ryzin, M. J., \& Dishion, T. J. (2015). Alcohol, marijuana and tobacco use trajectories from age 12 to 24 years: Demographic correlates and young adult substance use problems. Development and Psychopathology, 27 (Special Issue 01), 253-277. 
Noonan, D., \& Kulbok, P. A. (2009). New tobacco trends: Waterpipe (hookah) smoking and implications for health-care providers. Journal of the American Academy of Nurse Practitioners, 21(5), 258-260.

Pløddemann, A., Dada, S., Williams, Y., Bhana, A., Pereira, A., Nel, E., ... Fourie, D. (2010). South African Community Epidemiology Network on Drug Use (SACENDU) Report:

Monitoring alcohol and drug abuse trends in South Africa, Phase 27. July to December 2009. Cape Town, South Africa: Medical Research Council.

Primack, B. A., Aronson, J. D., \& Agarwal, A. A. (2006). An old custom, a new threat to tobacco control. American Journal of Public Health, 96(8), 1339.

Reddy, S. P., James, S., Sewpaul, R., Koopman, F., Funani, N. I., Sifunda, S.,... Omardien, R. G. (2010). Umthente Uhlaba Usamila-The South African Youth Risk Behaviour Survey 2008. Cape Town, South Africa: South African Medical Research Council.

Rice, V. H., Templin, T., \& Kulwicki, A. (2003). Arab American tobacco use: Four pilot studies. Preventive Medicine, 37, 492-498.

Ryan, J., Roman, N. V., \& Okwany, A. (2015). The effects of parental monitoring and communication on adolescent substance use and risky sexual activity: A systematic review. Open Family Studies Journal, 7(1), 12-27.

Sabahy, A. R., Divsalar, K., \& Nakhaee, N. (2011). Attitude of university students towards waterpipe smoking: Study in Iran. Addiction \&Health, 3(1-2), 9.

Senkubuge, F., Ayo-Yusuf, O. A., Louwagie, G. M., \& Okuyemi, K. S. (2012). Water pipe and smokeless tobacco use among medical students in South Africa. Nicotine \& Tobacco Research, 14(6), 755-760.

Shihadeh, A., \& Saleh, R. (2005). Polycyclic aromatic hydrocarbons, carbon monoxide, "tar," and nicotine in the mainstream smoke aerosol of the narghile water pipe. Food and Chemical Toxicology, 43(5), 655-661.

Sutfin, E. L., Song, E. Y., Reboussin, B. A., \& Wolfson, M. (2014). What are young adults smoking in their hookahs? A latent class analysis of substances smoked. Addictive Behaviors, 39(7), 1191-1196.

Tamim, H., Al-Sahab, B., Akkary, G., Ghanem, M., Tamim, N., El Roueiheb, Z.,... Afifi, R. (2007). Cigarette and nargileh smoking practices among school students in Beirut, Lebanon. American Journal of Health Behavior, 31(1), 56-63.

Telzer, E. H., Gonzales, N., \& Fuligni, A. J. (2014). Family obligation values and family assistance behaviors: Protective and risk factors for Mexican-American adolescents' substance use. Journal of Youth and Adolescence, 43(2), 270-283.

Theron, A., Schultz, C., Ker, J. A., \& Falzone, N. (2010). Carboxyhaemoglobin levels in waterpipe and cigarette smokers. South African MedicalJournal,100(2), 122-124.

Van Der Merwe, N., Banoobhai, T., Gqweta, A., Gwala, A., Masiea, T. Misra, M., \& Zweigenthal, V. (2013). Hookah pipe smoking among health sciences students. South African Medical Journal, 103(11), 847-849.

Weglicki, L. S., Templin, T. N., Rice, V. H., Jamil, H., \& Hammad, A. (2008). Comparison of cigarette and water-pipe smoking by Arab and non-Arab-American youth. American Journal of Preventive Medicine, 35(4), 334-339. 
World Health Organization. (2005). Waterpipe tobacco smoking: Health effects, research needs and recommended actions by regulators. Geneva, Switzerland: World Health Organization Switzerland.

World Health Organization. (2013). WHO report on the global tobacco epidemic: Enforcing bans on tobacco advertising, promotion and sponsorship. Geneva, Switzerland: World Health Organization Switzerland.

World Health Organization. (2015). Waterpipe tobacco smoking: Health effects, research needs and recommended actions by regulators (2nd ed.). Geneva, Switzerland: World Health Organization Switzerland. 